\title{
Progressive Ankylosis Gene (ank) Regulates Osteoblast Differentiation
}

\author{
Thorsten Kirsch ${ }^{a}$ Hyon Jong Kim ${ }^{a}$ Jeffrey A. Winkles ${ }^{b}$ \\ ${ }^{a}$ Department of Orthopaedics, Musculoskeletal Research Laboratories, and ${ }^{b}$ Department of Surgery, Center \\ for Vascular and Inflammatory Diseases, University of Maryland School of Medicine, Baltimore, Md., USA
}

\section{Key Words}

Differentiation · Osteoblasts $\cdot$ Osterix $\cdot$ Phosphate $\cdot$

Progressive ankylosis gene $\cdot$ Runx 2

\begin{abstract}
The progressive ankylosis gene (ank) is a transmembrane protein that transports intracellular pyrophosphate to the extracellular milieu. Human mutations of ank lead to craniometaphyseal dysplasia, a disease which is characterized by the overgrowth of craniofacial bones and osteopenia in long bones, suggesting that ANK plays a regulatory role in osteoblast differentiation. To determine the role of ANK in osteoblast differentiation, we suppressed ANK expression in the osteoblastic MC3T3-E1 cell line using siRNA and determined the expression of osteoblastic marker genes and the transcription factors osterix and runx2. In addition, we determined the osteoblastic differentiation of bone marrow stromal cells isolated from the bone marrow of ank/ank mice, which express a truncated, nonfunctional ANK protein, or wild-type littermates. Suppression of ANK expression in MC3T3-E1 cells led to a decrease in bone marker gene expression, including alkaline phosphatase, bone sialoprotein, osteocalcin and type I collagen. In addition, osterix gene expression was decreased in ANK expression-suppressed MC3T3 cells, whereas runx2 expression was increased. Bone marrow stromal cells isolated from ank/ank mice cultured in
\end{abstract}

the presence of ascorbate-2-phosphate for up to 35 days showed markedly reduced mineralization compared to the mineralization of bone marrow stromal cells isolated from wild-type littermates. In conclusion, these findings suggest that ANK is a positive regulator of differentiation events towards a mature osteoblastic phenotype.

Copyright $\odot 2008$ S. Karger AG, Basel

\section{Introduction}

The progressive ankylosis gene (ank) is a transmembrane protein that transports intracellular pyrophosphate $\left(\mathrm{PP}_{\mathrm{i}}\right)$ to the extracellular milieu [Ho et al., 2000]. Recently, human mutations in ank have been discovered that lead to craniometaphyseal dysplasia [Nurnberg et al., 2001; Reichenberger et al., 2001]. This disease is characterized by an overgrowth of craniofacial and long bones, suggesting that ANK plays a regulatory role in osteoblast differentiation.

\section{Abbreviations used in this paper \\ APase alkaline phosphatase \\ PFA phosphoformic acid \\ $\mathrm{PP}_{\mathrm{i}} \quad$ pyrophosphate}

\section{KARGER}

๑ 2008 S. Karger AG, Basel

Fax +41613061234

E-Mail karger@karger.ch

www.karger.com
Accessible online at: www.karger.com/cto
Dr. Thorsten Kirsch

Musculoskeletal Research Center, Department of Orthopaedic Surgery

NYU School of Medicine, Hospital for Joint Diseases

301 East 17th Street, Suite 1500, New York, NY 10003 (USA)

Tel. +1 212598 6589, Fax +1 212598 6096, E-Mail Thorsten.Kirsch@nyumc.org 
The transcriptional program that controls osteoblastogenesis is initiated with the early developmental signals that recruit mesenchymal stem cells to organize an embryonic bone directly by osteoblast differentiation (intramembranous bone) or mesenchymal stem cell condensation into a cartilage template for endochondral bone formation. Chondrocytes in this cartilage template undergo terminal differentiation and apoptosis and are eventually replaced by bone-forming osteoblasts. The transcription factor $r u n \times 2 / c b f a 1$, a runt family polypeptide, has been recently described as the master regulator for osteoblastic differentiation. In runx2/cbfa1 null mice, osteoblast differentiation is arrested in both the endochondral and intramembranous skeleton [Ducy et al., 1997; Komori et al., 1997; Otto et al., 1997]. runx2 expression has been shown to be upregulated early during osteoblastic differentiation and it has been suggested that increased runx2 expression in mesenchymal stem cells results in the differentiation into an osteoblastic precursor cell. runx2 has been shown to be expressed during the entire differentiation process of these osteoblastic precursor cells into mature osteoblasts [Lian et al., 2004; Komori, 2005, 2006]. Another transcription factor, osterix, has been recently discovered, which also plays a critical role in osteoblastogenic differentiation [Nakashima et al., 2002]. osterix null mice also show a complete lack of both intramembranous and endochondral ossification due to the absence of osteoblast differentiation. runx2 is expressed in the mesenchymal cells of osterix null mice, whereas osterix is not expressed in runx 2 null mice [Nakashima et al., 2002]. Therefore, osterix is a downstream gene of runx2 and it was suggested that osterix controls the differentiation of an osteoblastic precursor cell into an immature osteoblast [Komori, 2006; Huang et al., 2007]. The determination of factors and their roles in regulating the expression of these transcription factors is crucial. Based on the findings that human mutations in ANK result in an overgrowth of craniofacial bone and an osteopenic phenotype of long bones, we hypothesized that ANK may play a role in regulating the expression of these transcription factors and ultimately osteoblastic differentiation.

\section{Materials and Methods}

\section{MC3T3 Cell Culture}

The osteoblastic cell line MC3T3-E1 was cultured at confluence in Dulbecco's modified Eagle's medium with $10 \%$ fetal calf serum and then cultured in the presence of ascorbate $(50 \mu \mathrm{g} / \mathrm{ml})$ and $\beta$-glycerophosphate $(10 \mathrm{mM})$ to induce collagenous matrix release and mineralization (differentiation medium). Cells were cultured for up to 20 days in differentiation medium in the absence or presence of phosphoformic acid (PFA, $1 \mathrm{mM}$ ). For siRNA experiments, cells were transfected with control siRNA and ank-specific siRNA using the siPORT NeoFX reagent from Ambion. After transfection, cells were cultured for up to 12 days in differentiation medium. Real-time PCR analysis using SYBR Green was performed as described previously [Wang et al., 2005]. The 18 S RNA was amplified at the same time and used as an internal control. The cycle threshold values for 18S RNA and the samples were measured and calculated by computer software. Relative transcription levels were calculated as $\mathrm{x}=2^{-\Delta \Delta \mathrm{CT}}$, where $\Delta \Delta \mathrm{CT}=\Delta \mathrm{E}-\Delta \mathrm{C}, \Delta \mathrm{E}=\mathrm{Ct}_{\mathrm{exp}}-\mathrm{Ct}_{18 \mathrm{~S}}$ and $\Delta \mathrm{C}=\mathrm{Ct}_{\mathrm{ctrl}}-$ $\mathrm{Ct}_{18 \mathrm{~s}}$.

\section{Mouse Bone Marrow Stromal Cell Culture}

Bone marrow stromal cells were isolated from femurs of 4week-old ank/ank mice or wild-type littermates and cultured at $2 \times 10^{6}$ cells per $10-\mathrm{cm}^{2}$ well in $\alpha$-MEM supplemented with $15 \%$ fetal calf serum. After cells had reached confluency, $100 \mu \mathrm{g} / \mathrm{ml}$ ascorbate-2-phosphate was added and cells were cultured for up to 35 days. Van Kossa staining (mineralization) was performed after 35 days.

\section{Results}

MC3T3-E1 cells showed the highest expression of ANK on day 3 after addition of differentiation medium. After day 3, ANK expression declined. Contrarily, alkaline phosphatase (APase) expression started to increase on day 8 and reached its maximum between day 17 and 20 , whereas mineralization occurred on day 20 (data not shown). To determine the function of ANK in osteoblastic differentiation, we transfected MC3T3-E1 cells with $30 \mathrm{nM}$ of siRNA specific for ank and cultured these cells in differentiation medium for various time points. Immunoblot analysis showed a marked reduction of ANK protein expression in ank-specific siRNA-transfected cells after 3 days of culture in differentiation medium, whereas transfection with the same concentration of control siRNA did not affect ANK expression compared to the ANK expression levels of nontransfected cells (fig. 1a). Suppression of ANK expression resulted in a decrease in bone marker gene expression, including APase, type I collagen, bone sialoprotein, and osteocalcin, compared to the expression levels of these genes in nontransfected cells or cells transfected with control siRNA (fig. 1b). In addition, osterix expression was downregulated in ANK expression-suppressed MC3T3-E1 cells, whereas runx2 expression was increased in these cells (fig. 1b). To determine whether extracellular $\mathrm{PP}_{\mathrm{i}}$ (resulting from the transport of intracellular $\mathrm{PP}_{\mathrm{i}}$ by ANK to the extracellular mi- 


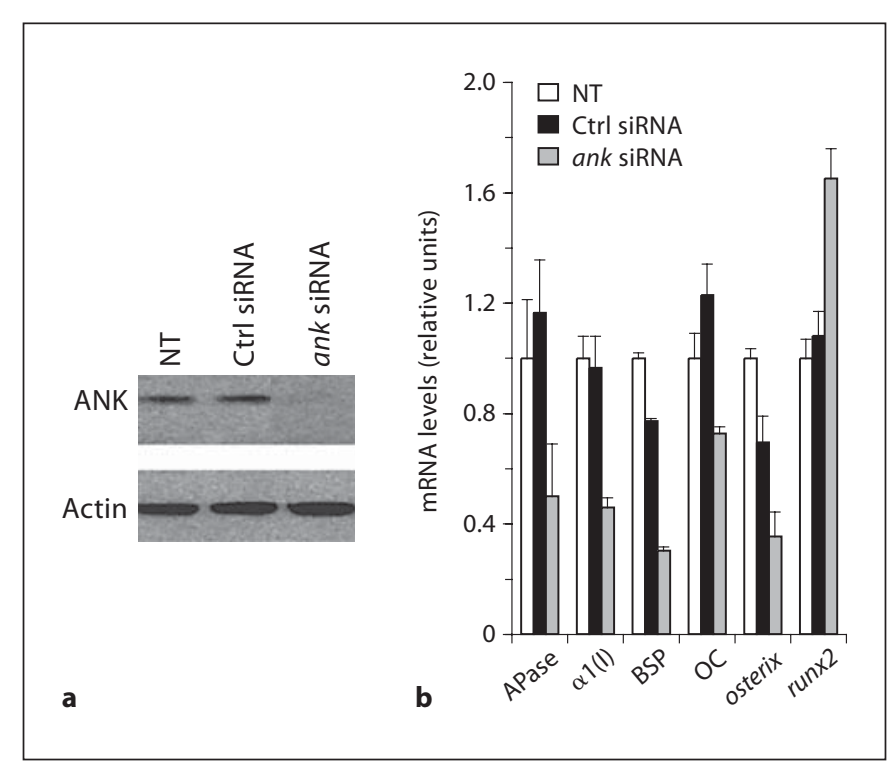

Fig. 1. The effect of ANK on osteoblastic differentiation of MC3T3-E1 cell line. a Immunoblot analysis of ANK protein expression in nontransfected (NT), control siRNA-transfected (Ctrl siRNA) and ank-specific siRNA-transfected (ank siRNA) MC3T3E1 cells after 3 days of transfection. b Gene expression of APase, type I collagen $[\alpha 1(\mathrm{I})]$, bone sialoprotein (BSP), osteocalcin (OC), osterix and runx2 in nontransfected (NT), control siRNA-transfected (Ctrl siRNA) and $a n k$-specific siRNA-transfected (ank siRNA) MC3T3-E1 cells after 8 days of transfection. Gene expression of APase, $\alpha 1(\mathrm{I})$, BSP, OC and osterix was detected using quantitative real-time PCR analysis and SYBR Green.

lieu) or extracellular inorganic phosphate resulting from the hydrolysis of extracellular $\mathrm{PP}_{\mathrm{i}}$ by APase acts as the signaling molecule affecting osteoblast differentiation, we cultured MC3T3 cells in differentiation medium in the absence or presence of PFA. PFA has been shown to inhibit sodium/phosphate cotransporters that transport inorganic phosphate into the cell including osteoblasts [Beck, 2003]. PFA treatment inhibited APase activity of MC3T3 cells (fig. 2). Next, we isolated bone marrow stromal cells from ank/ank mice and wild-type littermates. ank/ank mice express a truncated, nonfunctional ANK protein [Ho et al., 2000]. Osteogenic differentiation of bone marrow stromal cells was induced by the addition of ascorbate-2-phosphate (osteogenic medium) as described previously [Abe et al., 2000]. Bone marrow stromal cells isolated from ank/ank mice showed notable less mineralization after 35 days of culture in osteogenic medium than bone marrow stromal cells isolated from wild-type littermates, as revealed by van Kossa staining (fig. 3).

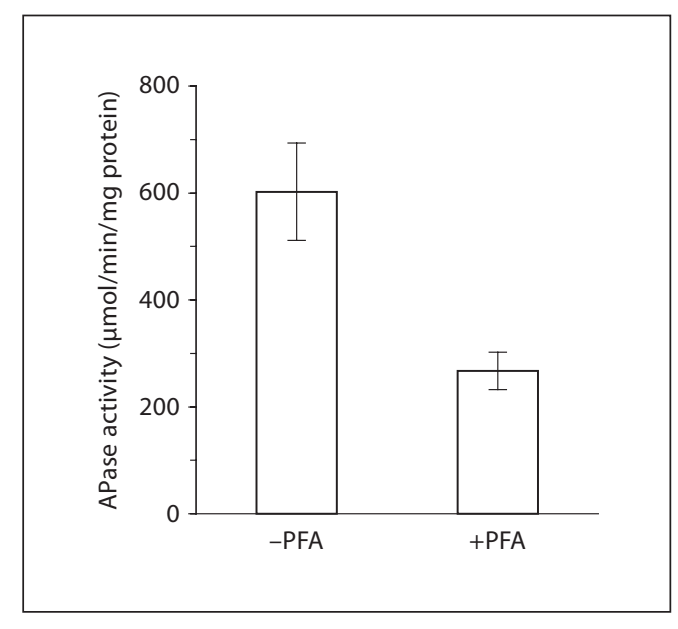

Fig. 2. APase activity of PFA-untreated (-PFA) and PFA-treated (+PFA) MC3T3 cells after culture for 8 days in differentiation medium.

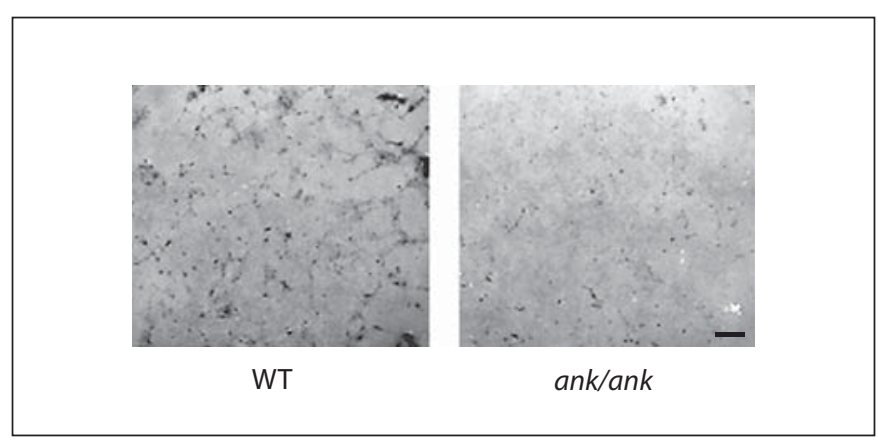

Fig. 3. Effect of ANK on osteoblastic differentiation of bone marrow stromal cells. Bone marrow stromal cells were isolated from ank/ank mice and wild-type (WT) littermates and cultured for various time points in the presence of ascorbate-2-phosphate. Van Kossa staining to detect mineralization was performed after 35 days of culture. Mineralization of bone marrow stromal cells isolated from ank/ank mice was markedly reduced compared to mineralization of bone marrow stromal cells isolated from wild-type littermates. Scale bar $=100 \mu \mathrm{m}$.

\section{Discussion}

Our findings, showing that suppression of ANK expression in the osteoblastic cell line MC3T3-E1 decreased the expression of osteoblastic marker genes and osterix, suggest that ANK regulates osteoblast differentiation by acting as a positive regulator on the differentiation of preosteoblastic cells into immature osteoblasts. Osterix is a transcription factor that has been implicated in the regu- 
lation of differentiation of preosteoblastic cells into immature osteoblasts [Komori, 2006; Huang et al., 2007]. runx2 expression was increased in ANK expression-suppressed MC3T3 cells. Interestingly, a previous study has shown that overexpression of runx2 in immature osteoblasts results in an osteopenic phenotype, suggesting that runx2 inhibits osteoblast maturation and needs to be suppressed for osteoblast and bone maturation to occur [Komori, 2008]. Furthermore, our findings, showing that PFA inhibits osteoblastic differentiation of MC3T3 cells, suggest that not the extracellular $\mathrm{PP}_{\mathrm{i}}$ directly resulting from ANK transport but inorganic phosphate resulting from the hydrolysis of this $\mathrm{PP}_{\mathrm{i}}$ is being transported back into the cell and then acts as a signaling molecule regulating osteoblastic differentiation of precursor cells. ANK also regulated the differentiation of bone marrow stromal cells into osteoblasts. Lack of a functional ANK resulted in a delayed differentiation of these cells into osteoblasts.

The lack of ANK function in humans and mice results in thickened craniofacial bones, whereas the long bones show an osteopenic phenotype [Gurley et al., 2006]. The results of our study, showing that ANK is required for the differentiation of preosteoblastic cells into immature osteoblasts, are in accordance with osteopenia of the long bones in individuals with suppressed ANK function. However, how can the thickening of the craniofacial bones be explained in individuals lacking ANK function? One explanation is the different origin of osteoblastic cells forming the long bones and the calvarial bones [Toma et al., 1997]. Another explanation is that preosteoblastic cells in ANK-suppressed individuals undergo chondrocytic differentiation during long bone formation and are therefore lost from the osteoblastic lineage, whereas preosteoblastic cells do not undergo chondrocytic differentiation in calvarial bones, but rather accumulate and eventually undergo maturation and form more bone than being formed in individuals with normal ANK function. Interestingly, osterix, which is downregulated in ANK-suppressed MC3T3-E1 cells, has been shown to inhibit the differentiation of preosteoblastic cells along the chond rocytic lineage [Huang et al., 2007]. In the cranium, however, other environmental factors besides osterix are present, which prevent the chondrocytic differentiation of preosteoblastic cells [Toma et al., 1997]. Finally, long bones undergo more and rapid remodeling than craniofacial bones. These remodeling processes need the rapid maturation of preosteoblastic cells into immature and ultimately mature osteoblasts.

In conclusion, our findings provide evidence that ANK plays an important role in early osteoblastic differentiation and acts as a positive regulator of the differentiation of preosteoblastic precursor cells into immature osteoblasts.

\section{Acknowledgement}

This study was funded by grants from NIAMS/NIH (R01AR046245 and R01AR049074) to T.K.
References

ANK and Osteoblast Differentiation

\footnotetext{
Abe, E., M. Yamamoto, Y. Taguchi, B. Lecka- Ho, A.M., M.D. Johnson, D.M. Kingsley (2000) Czernik, C.A. O’Brien, A.N. Economides, N. Stahl, R.L. Jilka, S.C. Manolagas (2000) Essential requirement of BMPs-2/4 for both osteoblast and osteoclast formation in murine bone marrow cultures from adult mice: antagonism by noggin. J Bone Miner Res 15: 663-673.

Beck, G.R. Jr. (2003) Inorganic phosphate as a signaling molecule. J Cell Biochem 90: 234243.

Ducy, P., R. Zhang, V. Geoffroy, A.L. Ridall, G. Karsenty (1997) Osf2/Cbfa1:a transcriptional activator of osteoblast differentiation. Cell 89: 747-754.

Gurley, K.A., R.J. Reimer, D.M. Kingsley (2006) Biochemical and genetic analysis of ANK in Role of the mouse ank gene in control of tissue calcification and arthritis. Science 289: 265-270.

Huang, W., S. Yang, J. Shao, Y.P. Li (2007) Signaling and transcriptional regulation in osteoblast commitment and differentiation. Front Biosci 12: 3068-3092.

Komori, T. (2005) Regulation of skeletal development by the Runx family of transcription factors. J Cell Biochem 95: 445-453.

Komori, T. (2006) Regulation of osteoblast differentiation by transcription factors. J Cell Biochem 99: 1233-1239.

Komori, T. (2008) Regulation of bone development and maintenance by Runx2. Front Biosci 13: 898-903.
} arthritis and bone disease. Am J Hum Genet 79: 1017-1029. 
Komori, T., H. Yagi, S. Nomura, A. Yamaguchi, K. Sasaki, K. Deguchi, Y. Shimizu, R.T. Bronson, Y.H. Gao, M. Inada, M. Sato, R. Okamoto, Y. Kitamura, S. Yoshiki, T. Kishimoto (1997) Targeted disruption of Cbfa1 results in a complete lack of bone formation owing to maturational arrest of osteoblasts. Cell 89: 755-764.

Lian, J.B., A. Javed, S.K. Zaidi, C. Lengner, M. Montecino, A.J. van Wijnen, J.L. Stein, G.S. Stein (2004) Regulatory controls for osteoblast growth and differentiation: role of Runx/Cbfa/AML factors. Crit Rev Eukaryot Gene Expr 14: 1-41.

Nakashima, K., X. Zhou, G. Kunkel, Z. Zhang, J.M. Deng, R.R. Behringer, B. de Crombrugghe (2002) The novel zinc finger-containing transcription factor osterix is required for osteoblast differentiation and bone formation. Cell 108: 17-29.
Nurnberg, P., H. Thiele, D. Chandler, W. Hohne, M.L. Cunningham, H. Ritter, G. Leschik, K. Uhlmann, C. Mischung, K. Harrop, J. Goldblatt, Z.U. Borochowitz, D. Kotzot, F. Westermann, S. Mundlos, H.S. Braun, N. Laing, S. Tinschert (2001) Heterozygous mutations in $\mathrm{ANKH}$, the human ortholog of the mouse progressive ankylosis gene, result in craniometaphyseal dysplasia. Nat Genet 28: 37-41.

Otto, F., A.P. Thornell, T. Crompton, A. Denzel, K.C. Gilmour, I.R. Rosewell, G.W. Stamp, R.S. Beddington, S. Mundlos, B.R. Olsen, P. B. Selby, M.J. Owen (1997) Cbfa1, a candidate gene for cleidocranial dysplasia syndrome, is essential for osteoblast differentiation and bone development. Cell 89: 765-771.
Reichenberger, E., V. Tiziani, S. Watanabe, L. Park, Y. Ueki, C. Santanna, S.T. Baur, R. Shiang, D.K. Grange, P. Beighton, J. Gardner, H. Hamersma, S. Sellars, R. Ramesar, A.C. Lidral, A. Sommer, C.M. Raposo do Amaral, R.J. Gorlin, J.B. Mulliken, B.R. Olsen (2001) Autosomal dominant craniometaphyseal dysplasia is caused by mutations in the transmembrane protein ANK. Am J Hum Genet 68: 1321-1326.

Toma, C.D., J.L. Schaffer, M.C. Meazzini, D. Zurakowski, H.D. Nah, L.C. Gerstenfeld (1997) Developmental restriction of embryonic calvarial cell populations as characterized by their in vitro potential for chondrogenic differentiation. J Bone Miner Res 12: 2024-2039.

-Wang, W., J. Xu, T. Kirsch (2005) Annexin V and terminal differentiation of growth plate chondrocytes. Exp Cell Res 305: 156-165. 